\title{
Entrevista com Cristine Legare
}

\author{
Heslley Machado Silva ${ }^{1}$
}

${ }^{1}$ Centro Universitário de Formiga (UNIFOR-MG)

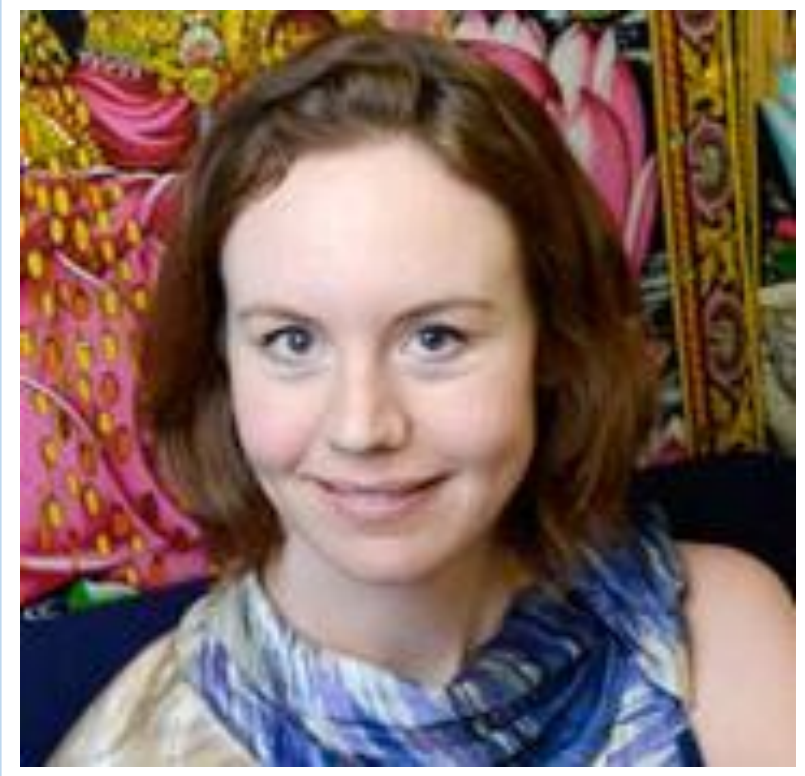

Cristine Legare é professora e diretora do Laboratório de Evolução e Ontogênese do Aprendizado da Universidade do Texas em Austin. Sua pesquisa examina como a mente humana nos permite aprender, criar $e$ transmitir cultura. Ela realiza comparações entre idade, cultura e espécie para abordar questões fundamentais sobre evolução cognitiva e cultural.

Sua pesquisa e treinamento refletem seu compromisso com uma abordagem interdisciplinar ao estudo do desenvolvimento cognitiva. Ela baseia-se em conhecimentos da psicologia cognitiva, cultural, de desenvolvimento, educacional e evolucionária, bem como da antropologia e filosofia cognitiva e evolutiva, com o objetivo de facilitar a fertilização cruzada e entre essas disciplinas. Na graduação, ela fez cursos em várias disciplinas de ciências sociais, com formação dupla em desenvolvimento humano e estudos culturais na Universidade da Califórnia, em San Diego. Na pósgraduação, ela participou do Programa de Cultura e Cognição enquanto completava seu doutorado em psicologia do desenvolvimento na Universidade de Michigan.

A pesquisa de Cristine foi publicada em mais de 60 artigos científicos em revistas, incluindo Psychological Science, Trends in Cognitive Sciences, Proceedings of the National Academy of Sciences, Child Development, Developmental Psychology, Cognitive Psychology, Cognition, and Evolution, e Human Behavior, e foi coberta por uma série de veículos de mídia, incluindo NPR, Nature, The Wall Street Journal, e Scientific American. Suas pesquisas receberam financiamento do Economic and Social Research Council (UK), da National Science Foundation, da McDonnell Foundation, da John Templeton Foundation $e$ do National Evolutionary Synthesis Center (NESCent). Cristine foi reconhecida com o Prêmio APS Janet Taylor Spence 2015 para Contribuições de Carreira Transformativa e o Prêmio APA Boyd McCandless 2016 por sua pesquisa sobre a evolução e a ontogenia da cognição e da cultura. 
1. Nos fale brevemente sobre sua trajetória, de Antropologia a Psicologia, chegando a estudos sobre a Evolução. Por que o interesse particular sobre esse tópico?

A evolução fornece uma base teórica para o estudo da cognição humana, do comportamento e da cultura. Eu vejo os campos da antropologia e da psicologia fornecendo conjuntos de ferramentas complementares para o estudo dos fenômenos científicos sociais. Ambas as disciplinas são necessárias para conduzir pesquisas comparativas entre o desenvolvimento, as culturas e as espécies.

2. Além de professora, você é diretora do laboratório de Evolução, Variação e Ontogênese do Aprendizado da Universidade do Texas em Austin, um centro de grande produção acadêmica. Nos conte um pouco sobre as pesquisas desenvolvidas por esse laboratório.

Conduzimos a ciência cognitiva aplicada. Isso implica em aplicar as ferramentas teóricas e metodológicas da ciência cognitiva para resolver problemas aplicados e responder perguntas abertas no desenvolvimento global, na educação internacional e na saúde pública.

3. Os seus estudos têm diversas interfaces para entender a sociedade, a cultura e a evolução, a pandemia tem afetado a humanidade de sobremaneira. Há planos para se investigar a questão da epidemia em curso da COVID-19 e as consequências desse momento difícil?

Atualmente estamos elaborando um estudo internacional em larga escala com colaboradores e participantes de 30 países ao redor do mundo para examinar a continuidade cultural e a variação de como as pessoas raciocinam sobre a causa, propagação, risco e impacto da COVID-19.

4. Compartilhe conosco a pesquisa que você desenvolveu que considera mais relevante, é claro que todas são, mas aquela que lhe deu mais prazer pelas descobertas e pelos resultados alcançados. Dê uma amostra para os jovens estudantes brasileiros como a investigação pode ser gratificante.

Um dos meus estudos favoritos foi realizado no Brasil. Examinamos como as pessoas raciocinam sobre a eficácia das simpatias, e descobrimos que o raciocínio sobre a eficácia deste tipo de rituais revela preconceitos universais na forma como processamos as informações causais. Esta pesquisa utilizou um sistema de crenças culturalmente específico para desvendar processos cognitivos universais. A pesquisa que mais me entusiasma ilustra a universalidade, bem como a flexibilidade e a diversidade da mente humana.

5. Uma das grandes dificuldades encontradas na pesquisa brasileira é o financiamento regular das investigações. Você tem muitas pesquisas bancadas por diversas agências, nos conte um pouco algumas razões do sucesso nesse financiamento.

Recomendo a aplicação a uma série de financiadores, incluindo fundações que financiam pesquisas internacionais. O governo federal é uma importante fonte de financiamento, mas é uma das muitas fontes de financiamento de pesquisa disponíveis. É muito importante ser responsivo ao feedback sobre seu trabalho e perseverar. Muitas vezes são necessárias múltiplas aplicações antes que sua pesquisa seja financiada.

6. Outro dado interessante sobre sua trajetória acadêmica é a grande produção e publicação de artigos. Os pesquisadores brasileiros são muito cobrados nesse sentido. Apresente algumas dicas para uma elaboração de artigos de qualidade a serem publicados nas melhores revistas.

Minha formação interdisciplinar em antropologia e biologia tem sido muito útil na abordagem de questões psicológicas de forma inovadora. Leia fora de sua disciplina, e colabore com pessoas que não têm experiência idêntica. Aprenda as questões centrais de pesquisa em sua disciplina, e estude-as de forma criativa. Também é fundamental investir em treinamento estatístico de ponta e aprimorar suas habilidades de escrita.

7. Você esteve recentemente na Universidade de São Paulo (USP), no Brasil, e desenvolveu o Workshop "Abordagens Evolucionista da Cultura" (2019). Nos fale um pouco sobre esse workshop e quais suas impressões sobre o Brasil, a pesquisa brasileira e os estudantes.

A oficina foi sobre evolução cognitiva e cultural, tópicos que me entusiasmam muito. Aprendi muito sobre as excelentes pesquisas em andamento sobre estes temas na USP, e em universidades brasileiras de forma mais ampla. Fiquei extremamente impressionado com os talentosos professores e estudantes que conheci lá, e agora estou colaborando com um brasileiro, comportamentalista animal, que conheci no workshop.

8. Nos dê algumas sugestões de temas "quentes" da área acadêmica mundial e dos EUA que devem ser promissores nos próximos anos, que possam inspirar jovens $e$ não tão jovens pesquisadores brasileiros enveredarem.

O mundo está cada vez mais interconectado; a pandemia da COVID tornou isto impossível de negar. A globalização e a tecnologia aumentaram o ritmo de transmissão cultural, proporcionando oportunidades sem precedentes para estudar a mudança cultural, a transformação e a inovação. Também introduziu a desigualdade social e uma variedade de problemas socioecológicos que a população humana deve 
enfrentar em conjunto. As ciências sociais e biológicas devem assumir um papel ativo na tradução de conhecimentos básicos sobre cognição, comportamento e organizações sociais para enfrentar os problemas aplicados.

9. Apresente dificuldades que você percebe na área acadêmica e quais os caminhos que seu grupo busca para superá-las.

A insularidade das disciplinas acadêmicas continua a impedir o progresso. Os problemas que a humanidade e o mundo em geral enfrentam exigem as ferramentas e habilidades de múltiplas disciplinas científicas para resolvê-los. Eu supero isso colaborando com acadêmicos de outras disciplinas, e de outros países. Somos uma comunidade científica global, e devemos conduzir nossa ciência de acordo com isso.

10. Caso um jovem, nosso leitor, tenha interesse em ser seu orientando no laboratório em Austin, EUA, nos diga quais características um candidato dever ter, quais as habilidades mais desejadas? Quais as barreiras mais comuns para estudantes estrangeiros nos EUA?

Uma grande parte de meus alunos e do pessoal de pesquisa é e sempre foi internacional, o que tem sido fundamental para a qualidade e o impacto do meu trabalho. A ciência é uma empresa global, e eu recruto ativamente os melhores e mais brilhantes cientistas de todo o mundo. Procuro estudantes que estejam comprometidos com o estudo de tópicos críticos na ciência cognitiva. Criatividade, curiosidade, consciência, ética de trabalho e motivação são fundamentais, a cidadania é irrelevante para mim na escolha de com quem trabalho. Atualmente estou trabalhando com dois cientistas brasileiros, e tenho conduzido pesquisas no Brasil por uma década. Meu primeiro aluno de doutorado, André Souza, é de fato de Belo Horizonte. Ele foi professor em uma universidade americana e trabalhou para muitas das empresas de tecnologia de ponta. Ele é agora um pesquisador quantitativo sênior da Spotify. Meu conselho é procurar um supervisor que seja parte ativa da comunidade científica global. 